\title{
Corpus shakespeariano e reformas religiosas inglesas: um estudo de caso - O mercador de Veneza*
}

\author{
Alexander Martins Vianna ${ }^{* *}$
}

\section{RESUMO}

Os estudos pós-revisionistas sobre reformas religiosas inglesas têm focado as novas possibilidades de interpretação dos loci sociais, culturais e políticos de negociação da matéria religiosa na literatura e história da Inglaterra Reformada, evitando abordagens polarizadas whiggistas e revisionistas a respeito da história literária das reformas inglesas. Nesse sentido, este artigo aborda a materialidade textual do in-quarto de 1600 (Q1) de $O$ mercador de Vene$z a$ como um evento que localiza negociaçóes e expectativas culturais e políticas a respeito da conformação à religião oficial na Inglaterra elisabetana. Este artigo analisa especificamente a presença dos recursos retóricos no Q1 que figuram as ameaças 'puritanas' e 'papistas' à realeza sagrada, incluindo o estudo do uso dos temas da iconoclastia do mérito, da melancolia, da amiticia e da caritas na caracterização dos personagens principais.

Palavras-chave: Inglaterra; religião; drama; antipuritanismo; anticatolicismo.

\section{ABSTRACT}

Post-revisionist English Reformation studies have focused on new interpretation possibilities of social, political and cultural loci to religious negotiations in post-Reformation English History and Literature, avoiding Whiggist and revisionist polarized approaches to the Literary History of English Reformations. This article deals with the textual materiality of The Merchant of Venice $(\mathrm{Q} 1,1600)$ as an event that locates cultural and political negotiations, and expectations, regarding religion conformity in Elizabethan England. It especially intends to analyze the rhetorical motives used in Q1 to represent menaces to sacred kingship, and to figure its adversaries (namely 'Puritans' and 'Papists'), also including a study of propositions about iconoclasm of merits, melancholy, amiticia and caritas on the ways of fashioning the main characters' manners.

Keywords: England; religion; drama; anti-Puritanism; anti-Catholicism. 


\section{Introdução}

Os anos de propaganda do governo de Elizabeth da década de 1580 — que precedem a sua vitória, em 1588, sobre a Armada Invencível de Felipe II — foram marcados pela veiculação recorrente, por meio do teatro e dos sermóes episcopais, da ideia de que os 'puritanos' seriam ameaças internas que poderiam inadvertidamente minar a segurança do reino e, assim, possibilitar sua invasão pelas forças 'papistas' do Império Habsburgo. Desde a década de 1580, as companhias teatrais foram pensadas pelo governo elisabetano como um meio possível de veiculação de propagandas antipuritanas e anticatólicas, que reforçaram, haja vista a conjuntura cultural da controvérsia Marprelate (1588-1590), ${ }^{1}$ uma via de estereótipo de 'ameaça puritana' implicada com 'ameaça papista', cujo repertório tropológico e temático também pode ser identificado no jogo de antagonismo e caracterização dos personagens da peça $O$ mercador de Veneza.

Tais ponderaçóes de estudo se inscrevem num conjunto maior de problemas e objetos relacionados à virada crítica pós-revisionista na historiografia das reformas religiosas inglesas, quando houve a ampliação e o refino de hipóteses contextuais e intertextuais para as diferentes formas de estudos sobre as materializaçóes da linguagem religiosa na Inglaterra elisabetana: literatura, artes plásticas, panfletos, baladas, sermões, peças teatrais, tratados e justas teológicas, programas curriculares das universidades, iconografia, diários e memórias, relatórios de visitação eclesiástica, arquivos paroquiais e diocesanos, arquivos curiais, evidências orais ou escritas do folclore, evidências arqueológicas, processos nos tribunais eclesiásticos, livros de catecismos, livros de oração, materialidades bíblicas e outros meios e modos de localização da linguagem religiosa têm sido firmados como fontes potenciais nos estudos das reformas religiosas, evidenciando as tensôes sociopolíticas e as negociaçóes culturais em face dos dilemas de se estabelecer conformidade às expectativas conjunturais de ortodoxia religiosa. ${ }^{2}$

Em termos gerais, podemos falar, por um lado, de uma tendência anglo-saxã de pesquisas que mantêm algumas chaves críticas do revisionismo historiográfico da década de 1970 em relação ao paradigma historiográfico whiggista $^{3}$ de narrativas históricas e literárias

\footnotetext{
${ }^{1}$ POOLE, Kristen. Radical religion from Shakespeare to Milton: figures of nonconformity in Early Modern England. Cambridge: Cambridge University Press, 2006. p. 1-73.

${ }^{2}$ BATES, Lucy. The limits of possibility in England's Long Reformation. The Historical Journal, v. 53, n. 4, p. 1049-1070, 2010; FLETCHER, Anthony; ROBERTS, Peter (Ed.). Religion, culture and society in Early Modern Britain. Cambridge: Cambridge University Press, 1994; HUTTON, Ronald. The English Reformation and the evidence of folklore. Past \& Present, n. 148, p. 89-116, 1995; LAKE, Peter; QUESTIER, Michael. Agency, appropriation and rhetoric under the Gallows: puritans, romanist and the State in Early Modern England. Past \& Present, n. 153, p. 64-107, 1996; TODD, Margo et al. Reformation to Revolution: politics and religion in Early Modern England. Londres: Routledge, 1995; WALSHAM, Alexandra. 'Le théâtre des jugements de Dieu': le providentialisme et la réforme protestante dans l'Angleterre des XVI et XVII ${ }^{e}$ siècles. Histoire, Économie \& Société, Paris, v. 22, n. 3, p. 325-348, 2003.

${ }^{3} \mathrm{O}$ paradigma historiográfico whiggista centrava-se numa visão triunfalista e insular da Reforma Religiosa Inglesa (no singular) como a via media entre o calvinismo de Genebra e o catolicismo continental. Por
} 
nacionais, incluindo a crítica às abordagens de história das ideias que tratavam a produção intelectual das reformas inglesas na chave da excepcionalidade insular, ou seja, como algo isolado (tese da via media) dos embates, debates e soluçôes políticas, dinásticas e institucionais das reformas protestantes e católicas no continente europeu. ${ }^{4}$

Por outro lado, podemos falar especificamente da tendência historiográfica pós-revisionista, crítica das abordagens polarizadas dos revisionistas da década de 1970. Embora os revisionistas fossem críticos em relaçáo à polarização whiggista histórico-teleológica rei vs. parlamento - que desembocava na inevitabilidade histórica da Reforma Religiosa (no singular) e das Guerras Civis Confessionais da década de 1640 —, não deixaram também de criar suas próprias polarizaçôes historiográficas, centradas em algumas recorrentes tópicas de antagonismo: corte $v s$. país; indiferença ou resistência local $v$ s. centralizaçáo político-religiosa; religião oficial vs. culturas populares; religiâo oficial vs. recusantes; religiāo oficial vs. antinomianismo; ortodoxia vs. sectarismos; calvinismo vs. arminianismo etc. ${ }^{5}$ Como alternativa a tais tópicas de antagonismo na narrativa historiográfica, os pós-revisionistas valorizam premissas metodológicas centradas em noçôes como redes sociais, social agency, Long Reformation, negociação cultural, apropriação criativa, pragmática social e transação social no processo histórico de conformação da sociedade inglesa às religiôes reformadas (no plural). ${ }^{6}$

esse viés, a via media definiria a singularidade inglesa e seria o fundamento de sua modernidade cultural, social, política e econômica. A via média como tópos de modernidade inglesa foi recorrentemente colocada em contraste tipológico com o 'sectarismo puritano' e o 'atraso cultural' ou 'corrupção' católico. Até 1972, quando então houve a virada crítica revisionista da historiografia sobre as reformas religiosas inglesas (agora no plural), a história social e a história das ideias na Inglaterra associavam recorrentemente aos temas políticos e religiosos do paradigma whiggista os temas sociológicos (weberianos e marxistas) da secularização, desencantamento do mundo, revolução científica e revolução industrial para explicar o triunfo cultural, político e econômico da Inglaterra, ou seja, enfatizava-se o vínculo teleológico causal entre Reforma, iluminismo e revolução industrial, reforçando-se, ao adicionar premissas sociológicas e econômicas, os marcos paradigmáticos políticos e religiosos whiggistas de teleologia histórica de modernidade. No entanto, é importante lembrar que, antes da virada revisionista da década de 1970, as produçóes historiográficas de Christopher Hill das décadas de 1950 e 1960 formaram contribuiçóes importantes na positivação histórica do "sectarismo puritano" na Inglaterra, ao pensá-lo também como formador da modernidade, devido à sua tradição crítica de ideias e valores niveladores antiaristocráticos.

${ }^{4}$ AMOS, N. Scott. Martin Bucer and the revision of the Book of Common Prayer. Reformation \& Renaissance Review, v. 1, n. 2, p. 107-126, 1999; MACCULLOCH, Diarmaid; LAVEN, Mary; DUFFY, Eamon. Recent trends in the study of christianity in sixteenth-century Europe. Renaissance Quarterly, v. 59, n. 3, p. 697-731, 2006; MILTON, Anthony. Catholic and Reformed: the Roman and Protestant Churches in English protestant thought, 1600-1640. Cambridge: Cambridge University Press, 2002; SCOTT, Jonathan. England's troubles: seventeenth-century English political instability in European context. Cambridge: Cambridge University Press, 2000.

${ }^{5}$ MILTON, Anthony. Catholic and Reformed, op. cit.; PUJOL, Xavier Gil. Crónica y cuestiones de veinticinco ańos de debate. Pedralbes, v. 17, p. 241-288, 1997.

${ }^{6}$ CROCKETT, Bryan. The play of paradox: stage and sermon in renaissance England. Philadelphia: University of Pennsylvania Press, 1995; BATES, Lucy. The limits of possibility in England's Long Reformation. The Historical Journal, v. 53, n. 4, p. 1049-1070, 2010; WALSHAM, Alexandra. 'Le théâtre des jugements de 
Diferentemente dos revisionistas da década de 1970, os pós-revisionistas não formam uma frente historiográfica homogênea, mas tendem a evitar os excessos de seus predecessores críticos, deixando de tratar as reformas inglesas como simples imposiçôes conjunturais vindas de 'cima' (ortodoxias dos centros de poder) em face da 'indiferença religiosa', do 'sectarismo' ou do 'catolicismo residual e resistente' vindo de 'baixo' (localidades), equilibrando as abordagens sobre a relação entre mudança, continuidade e adaptaçóes pragmáticas ao observarem a dialética específica que há no longo e multifacético processo de instauração das reformas religiosas na Inglaterra. Tal tendência inclui um interesse renovado pelo fenômeno Godly, que, em vez de ser abordado como marginal, monolítico ou unidimensional ao longo dos séculos XVI e XVII, ${ }^{7}$ tem suscitado estudos interessados em analisar suas variaçôes figurativas, conforme época e local, em sermôes, propagandas oficiais, panfletos, querelas teológicas, processos judiciais, hagiografias, biografias apologéticas, diários, literatura e dramaturgia. $^{8}$

Como consequências da crítica ao paradigma historiográfico whiggista e aos paradigmas revisionistas da década de 1970, os estudos das reformas religiosas inglesas enfatizam abordagens que consideram o caráter contingente e tentativo das diferentes formas de materialização (e, portanto, manifestação e localização) da linguagem e da identidade religiosas. Contribuindo com esse enfoque, este artigo analisará o in-quarto de 1600 (Q1) da peça $O$ mercador de Veneza como um evento que localiza, em sua linguagem e materialidade textual, ${ }^{9}$ os embates religiosos da Inglaterra ao final do reinado (1558-1603) de Elizabeth I

Dieu': Le providentialisme et la Réforme protestante dans l'Angleterre des XVI ${ }^{e}$ et XVII ${ }^{e}$ siècles. Histoire, Économie \& Société, Paris, v. 22, n. 3, p. 325-348, 2003; PUJOL, Xavier Gil. Crónica y cuestiones de veinticinco ańos de debate, op. cit.

${ }^{7}$ Exemplos importantes dessa tradição crítica no pós-Segunda Guerra Mundial são: MORGAN, Edmund. Visible saints: the history of a puritan idea. Londres: Cornell University Press, 1965; NEW, John F. H. Anglican and Puritan: The basis of their opposition, 1558-1640. Stanford: Stanford University Press, 1964.

${ }^{8}$ BATES, Lucy. The limits of possibility in England's Long Reformation, op. cit.; MILTON, Anthony. Catholic and Reformed, op. cit.; PUJOL, Xavier Gil. Crónica y cuestiones de veinticinco años de debate, op. cit.; WALSHAM, Alexandra. 'Le théâtre des jugements de Dieu', op. cit.; MACCULLOCH, Diarmaid; LAVEN, Mary; DUFFY, Eamon. Recent trends in the study of christianity in sixteenth-century Europe, op. cit.; BREMER, Francis J. (Ed.). Puritanism: transatlantic perspectives on a seventeenth--century AngloAmerican faith. Boston: Massachusetts Historical Society, 1993; BERGAMASCO, Lucia. Hagiographie et sainteté en Angleterre aux XVI ${ }^{e}-X V I I^{e}$ siècles. Annales ESC, v. 48, n. 4, p. 1053-1085, 1993; TODD, Margo et al. Reformation to Revolution, op. cit.; COFFEY, John et al. The Cambridge companion to Puritanism. Cambridge: Cambridge University Press, 2008; JACKSON, Ken; MAROTTI, Arthur F. The turn to religion in Early Modern English studies. Criticism, v. 46, n. 1, p. 167-190, 2004; COLLINSON, Patrick. The religion of protestants: the Church in English society, 1559-1625 - the Oxford lectures, 1979. Oxford: Oxford University Press, 2003; LAKE, Peter. Popular form, puritan content? Two puritan appropriations of the murder pamphlet from mid-seventeenth-century London. In: FLETCHER, Anthony; ROBERTS, Peter (Ed.). Religion, culture and society in Early Modern Britain, op. cit.; LAKE, Peter. Moderate puritans and Elizabethan Church. Cambridge: Cambridge University Press, 2004; CROCKETT, Bryan. The play of paradox, op. cit.

${ }^{9}$ VIANNA, Alexander Martins. 'Shakespeare': um nome para textos. Topoi, v. 9, n. 16, p. 191-232, 2008. 
(1533-1603). Consideram-se, especificamente, a forma como se manifestam a caracterização dos personagens principais, a teleologia dramática e os temas e tópicas morais, políticos e teológicos que representam a ameaça ao corpo político e ao poder soberano.

\section{Shylock e Antônio como ameaças ao corpo político}

A trama central de $O$ mercador de Veneza pode ser resumida da seguinte forma: o melancólico, celibatário e rico comerciante Antônio avaliza um empréstimo para seu amigo Bassanio ter recursos para cortejar a rica, nobre e virginal herdeira de Belmonte, Portia; como seus recursos principais estavam todos empenhados em investimentos de além-mar, Antônio aceita os termos sangrentos, aparentemente irrealizáveis, do contrato de empréstimo feito com o rico judeu Shylock, que exige que a dívida, caso não pudesse ser honrada nos bens de além-mar, deveria ser paga com uma libra de carne do peito de Antônio; chega uma notícia equivocada, em Veneza, de que Antônio teria perdido todos os seus investimentos, criando a oportunidade para Shylock se vingar das muitas ofensas, no passado, que Antônio lhe causara; para resolver este paradoxo jurídico, Portia — já casada com Bassanio, mas ainda virgem - disfarça-se de juiz-advogado e, diante do duque de Veneza, consegue salvar a vida de Antônio sem causar dano às leis de Veneza.

Considerando a caracterização moral e dramática de Antônio e Shylock, pode ser oportuna a ideia de John Klause de que a tópica de antagonismo entre esses protagonistas deveria ser tratada mais na chave teológica da tensão entre os estereótipos cênicos de 'papista' e 'puritano' com paixões inconsistentes pelo absoluto do que a partir da questão do antissemitismo em Shakespeare. ${ }^{10}$ Klause náo afirma isso visando a amenizar o problema do antissemitismo na peça. No entanto, seu foco foi reconstituir uma legibilidade para o antagonismo dos personagens Antônio e Shylock, aventando a hipótese de caracterizá-los como inimigos confessionais 'papista' e 'puritano', mutuamente implicados, em suas açóes e escolhas, como ameaças à estabilidade das leis civis e do poder soberano.

Seguindo a tradição tropológica dos comentários bíblicos de Calvino, os atributos morais estereotipadores dos judeus no sermonário calvinista dos séculos XVI e XVII seriam: teimosia, obstinação, cegueira de mente/coraçâo, falta de espiritualidade e estupidez, o que era geralmente associado a uma concepção carnal e material de messias e à resistência de aceitar Jesus como messias. A consequência maior de sua estupidez seria os judeus terem se tornado um povo deicida. Outros atributos estereotípicos seriam: o senso arrogante de eleito e a centralidade referencial no Antigo Testamento. ${ }^{11} \mathrm{Na}$ Inglaterra elisabetana, os atributos de teimosia,

\footnotetext{
${ }^{10}$ KLAUSE, John. Catholic and protestant, jesuit and Jew: historical religion in The merchant of Venice. Religion and the Arts, v. 7, n. 1-2, p. 65-102, 2003.

${ }^{11}$ YARDENI, Myryam. French Calvinism and Judaism. Reformation \& Renaissance Review, v. 6, n. 3, p. 294-312, 2004.
} 
obstinação, cegueira de mentelcoração, espiritualidade hipócrita e estupidez, além do senso arrogante de eleito, da centralidade referencial no Antigo Testamento e do uso rigorista das leis civis, também poderiam compor o repertório dramático ${ }^{12}$ que faria, por exemplo, um leitor/audiência identificar o cênico judeu Shylock como um risível estereótipo teatral de 'puritano'.

Shylock é exclusivista em matéria de fé, não divide sua mesa com os 'cristãos' (i.e., com aqueles que considera ser réprobos), usa uma linguagem avessa ao ideal de plainness, ${ }^{13}$ faz alusôes recorrentes ao Antigo Testamento e faz a exigência (hipócrita/vingativa/carnal) de aplicaçáo rigorista (over-precise) ${ }^{14}$ das leis civis da fictícia Veneza em seu plano pessoal de vingança contra Antônio. Tudo isso caracterizá-lo-ia como um familiar, risível e perigoso 'puritano' de palco elizabethano. Além disso, outro indício familiar estaria compondo o estereótipo de 'puritano': Shylock proíbe sua filha Jessica de participar das diversôes e festas profanas do carnaval, o que seria uma marca dramática familiar de 'puritano' cênico que remontaria às 'controvérsias antiteatrais' da década de $1570 . .^{15}$

Embora a historiografia do teatro elizabethano já tenha revisado o fato de que nem todos que encaravam o teatro como uma 'escola de abusos' fossem puritanos nas controvérsias antiteatrais durante e após a década de $1570,{ }^{16}$ as apologias aos teatros — que os celebravam como instrumentos para o aguçamento do engenho e para a reforma moral do olhar, da mente e do coração - veicularam recorrentemente o estereótipo de 'puritano' como hipócrita e carnal rigorista moral, avesso ao período anual de solace régia. ${ }^{17}$ Aliás, vale lembrar que James VI (I), em Basilikon Doron (1599), dizia que os espetáculos públicos, festivais, peças teatrais, jogos honestos e exercícios de armas que compunham o período de solace régia serviam para deleitar seus súditos e reforçar os laços de amizade entre si e com o soberano. ${ }^{18}$ Portanto, também seriam uma expressão civil de caritas.

Ora, na fictícia Veneza da peça, as festas do carnaval — tratadas como perigosamente tentadoras por Shylock ${ }^{19}$ — não poderiam ocorrer sem o patronato ou a permissão do poder

\footnotetext{
${ }^{12}$ CROCKETT, Bryan. The play of paradox, op. cit.; DIEHL, Huston. 'Infinite space': representation and reformation in Measure for measure. Shakespeare Quarterly, v. 49, n. 4, p. 393-410, 1998.

${ }^{13}$ Ver: VIANNA, Alexander Martins. As figurações de rei e a caracterização de 'puritano' e 'papista' em Basilikon Doron. Topoi, v. 12, n. 22, p. 5-6, 2011.

${ }^{14}$ Ibid., p. 7-8.

${ }^{15}$ DIEHL, Huston. 'Infinite space', op. cit.; HAWKES, David. Idolatry and commodity fetishism in the antitheatrical controversy. Studies in English Literature 1500-1900, v. 39, n. 2, p. 255-273, 1999; CROCKETT, Bryan. The play of paradox, op. cit.

${ }^{16}$ WHITE, Paul Whitfield. Playing companies and the drama of the 1580s: a new direction for Elizabethan theatre history? Shakespeare Studies, n. 28, p. 265-284, 2000.

${ }^{17}$ DIEHL, Huston. Staging reform, reforming the stage: protestantism and popular theater in Early Modern England. Ithaca, NY: Cornell University Press, 1997. p. 67-93; CROCKETT, Bryan. The play of paradox, op. cit.

${ }^{18}$ VIANNA, Alexander Martins. As figuraçóes de rei e a caracterização de 'puritano' e 'papista' em Basilikon Doron, op. cit.

${ }^{19}$ HEYES, Thomas (Ed.). The most excellent historie of the merchant of Venice. Londres: Greene Dragon, 1600. p. 25.
} 
soberano (duque) e, emblematicamente, conturbam o exclusivismo religioso de Shylock ao possibilitar que sua filha construa enlace afetivo e fuja com um 'cristão' de baixa condição, o que significa a união de dois seres adversos e moralmente paradoxais numa ordem civil que, para se manter, oscila entre persuasão e força, entre a possibilidade da conversão desejada (Jessica) e a conversão forçada (Shylock) em 'cristão'. Assim, por meio da representação cênica de algo que era oficialmente concebido para deleitar os súditos e reforçar sua amiticia entre si e com o soberano, a peça ironicamente solapa o exclusivismo religioso de Shylock ao impossibilitar-lhe uma descendência 'judia/puritana'.

Portanto, (1) as representaçóes de tais festas na peça, (2) o seu significado moral de provocar ou manter a amiticia entre seres adversos e paradoxais que formam o Estado e (3) o incômodo exclusivista 'Santo' de Shylock com elas também serviriam para evocar, no leitor/ audiência elizabethano, a associação entre a figuração de Shylock e o estereótipo cênico de 'puritano' que pregava contra a solace régia. Afinal, pregar contra a solace régia seria equivalente à arrogância exclusivista 'precise' contra o poder soberano e os laços civis de amiticia, o que também equivale a ser um potencial fraturador do corpo político e opositor ao status quo episcopal representado pelo soberano. ${ }^{20}$

Como já foi apontada, a relação implicativa entre 'ameaça papista' e 'ameaça puritana' se tornou um tópos recorrente nas diferentes formas de manifestação de propagandas oficiais na Inglaterra, de Elizabeth I a James I, tanto que aparece na ediçấo de 1599 de Basilikon Doron, que era abertamente elogioso ao status quo episcopal elizabethano. Para justamente identificarmos como se processa em $O$ mercador de Veneza uma via de estereótipo de 'ameaça puritana' implicada com 'ameaça papista', devemos, agora, observar o repertório de motivos, tópicas e temas que caracterizariam Antônio como 'papista/jesuíta'. Para tanto, seguirei as evidências de paridade tropológica propostas por John Klause.

Algumas características temáticas da linguagem de Antônio aproxima-lo-iam, em chave moral negativa, ao mártir católico Robert Southwell (c. 1561-1595), que fora caçado, preso, interrogado, torturado e, por fim, esquartejado a mando do puritano moderado Richard Topcliffe (1531-1604), que servia diretamente a rainha Elizabeth na década de 1590. Nesta época, Topcliffe já era um reputado caçador de criptocatólicos e padres católicos - em sua maioria, jesuítas - em ação missionária clandestina na Inglaterra. Ora, se tais aspectos contextuais podem corroborar a hipótese de que a tópica de antagonismo entre Shylock e Antônio seria a figuração cênica, mais familiar na década de 1590, do choque mutuamente corrosivo entre 'puritano' e 'papista', há a possibilidade de ponderaçóes intertextuais que apontariam para o vínculo tropológico entre as figuraçóes de Antônio na peça e as figuraçôes de Southwell em suas correspondências. ${ }^{21}$

\footnotetext{
${ }^{20}$ VIANNA, Alexander Martins. As figuraçôes de rei e a caracterização de 'puritano' e 'papista' em Basilikon Doron, op. cit.; WHITE, Paul Whitfield. Playing companies and the drama of the 1580s, op. cit.; WALSHAM, Alexandra. 'Le théâtre des jugements de Dieu', op. cit.

${ }^{21}$ KLAUSE, John. Catholic and protestant, jesuit and Jew, op. cit.
} 
Em suas açôes missionárias sub-reptícias na Inglaterra elisabetana, os jesuítas costumavam assumir a identidade de mercadores em suas correspondências, tal como fizera Robert Southwell. Não por acaso, evocando tal correlação, Antônio é claramente caracterizado como um melancólico mercador celibatário sacrificial, mas, provocando a inversão cômica, a peça propóe sutilmente que a sua obra sacrificial é, no fundo, carnal: feita em nome de um amigo moralmente pouco meritoso, Bassanio, cujo nome é um trocadilho para "baixo", ou seja, homem sem valor, tanto no sentido de não ter posses quanto no sentido moral, pois é um perdulário muito dado a desonrosas juras casuais, ${ }^{22}$ que são dirigidas a Portia e a Antônio de forma concorrente.

$\mathrm{Na}$ figuração dos jogos de paradoxos da peça, Bassanio depende da tutela (moral, material e afetiva) de Antônio, que, por sua vez, é o pivô (1) a provocar sua inconstância de juramento a Portia, ${ }^{23}$ (2) a adiar a consumação do casamento entre Bassanio e Portia ${ }^{24}$ e (3) a deixar a herdeira de Belmonte - por meio de mais um juramento casual dirigido a Antônio - em ambígua situação de esposa preterida na cena do tribunal, ${ }^{25}$ o que metaforiza Portia, sutilmente, como "corno metafórico" 26 e justifica, ao final da peça, a punição cômica a Bassanio, quando Portia o torna, por um momento, "corno imaginário", ${ }^{27}$ evidenciando sua inabilidade efetiva de comandar — a não ser que Portia o permita - a castidade e a obediência de sua elevada esposa.

Em Antônio, há uma inconsequente paixão pelo absoluto, figurada em sua vontade de arriscar tudo pela felicidade do amigo, mas, tal como em vários momentos é sugerido na peça, há no love-amiticia celibatário e sacrificial dedicado por Antônio a Bassanio uma pretensão arrogante de colocá-lo acima do amor conjugal e da ordem civil. ${ }^{28}$ Daí, mesmo quando se configura o mundo do amor conjugal entre Portia e Bassanio em Belmonte, o status dramático de Antônio continua sendo de um outsider desestabilizador, ${ }^{29}$ como se figurasse um padre jesuíta abnegado no século, mas separado por uma distinção fundamental (o celibato) da congregaçáo dos laicos. Para evidenciar este aspecto, John Klause propóe a seguinte correspondência intertextual entre $O$ mercador de Veneza $(M V)$ e a Epistola de conforto $(E C)$ de Robert Southwell: ${ }^{30}$

\footnotetext{
${ }^{22}$ Nos séculos XVI e XVII, há uma grande quantidade de tratados que enfatizam a diferença entre jura casual e jura formal, assim como elucidam a desonra contida no uso casual do juramento ou promessa. Ver: TERRY, Reta A. 'Vows to the Blakest Devil': Hamlet and the evolving code of honor in Early Modern England. Renaissance Quarterly, v. 52, n. 4, p. 1076, 1999.

${ }^{23}$ HEYES, Thomas (Ed.). The most excellent historie of the merchant of Venice, op. cit. p. 65.

${ }^{24}$ Ibid., p. 46-47.

${ }^{25}$ Ibid., p. 60-61.

${ }^{26}$ Ibid., p. 69.

${ }^{27}$ Ibid., p. 73-74.

${ }^{28}$ HEYES, Thomas (Ed.). The most excellent historie of the merchant of Venice, op. cit. p. 60.

${ }^{29}$ Ibid., p. 73.

${ }^{30}$ Apud KLAUSE, John. Catholic and protestant, jesuit and Jew, op. cit.
} 
Commend me to your honorable wife.

Tell her the process of Antonio's end,

Say how I loved you, speak me fair in death;

And when the tale is told, bid her be judge

Whether Bassanio had not once a love. ${ }^{31}$

$M V, 4.1 .273-77$

Maiorem charitatem nemo habet, quam ut animam suam ponat quis, pro amicis suis.

Greater love than this no one hath, than that one lay down his life for his friends. ${ }^{32}$

$E C, 137 \mathrm{v}-138 \mathrm{r}$

A passagem de Robert Southwell, inspirada em João 15:13, cita a mensagem de Cristo ao mártir. Como Southwell assume a identidade de mercador em suas correspondências, termos como "hazard" e "venture" são utilizados para figurar positivamente a imensa capacidade de caritas do mártir católico, ${ }^{33}$ mas, na linguagem da peça, tal figuraçáo de sujeito católico sacrificial é deslocada para provocar um efeito iconoclasta contra a soteriologia católica. Como veremos ao tratar do tema da melancolia, a caritas de 'jesuíta' em Antônio torna-se um arrogante e ambíguo senso carnal de obra sacrificial. Não por acaso, a linguagem sacrificial da missão religiosa jesuítica de Southwell na Inglaterra - expressa por meio dos motivos temáticos de "ventura" e "risco" do comércio ultramarino em sua Suplicaçâo humilde à rainha Elizabeth $(H S)$ — é deliberadamente carnalizada no jogo de sedução entre Bassanio e Portia em Belmonte. Vejamos essa evidência de paridade tropológica entre $M V$ e $H S$ a partir de citaçóes diretas do próprio Klause: ${ }^{34}$

\footnotetext{
${ }^{31}$ Recomenda-me à vossa nobre esposa./ Conta-lhe como Antônio vivera./ Diga o quanto eu vos amo; e fale bem de mim quando minha vida findar./ E quando a lenda for contada, peça-lhe para julgar/ se Bassanio nunca teve antes um amor.

${ }^{32}$ Ninguém tem amor maior do que este: sacrificar sua vida por seus amigos.

${ }^{33}$ KLAUSE, John. Catholic and protestant, jesuit and Jew, op. cit.

${ }^{34}$ Apud KLAUSE, John. Catholic and protestant, jesuit and Jew, op. cit.
} 
Bass. (...) I live upon the rack.

Por. Ay, but I fear you speak upon the rack,

Where men enforced do speak anything.

$(M V, 3.2 .25-33)^{35}$

What unsufferable Agonies we have bene put to upon the Rack... [One so tortured] is apt to utter anything to abridge the sharpnes and severity of paine. [Yet even an] unskillful Lay man...[would] rather venture his life by saying too much, then hazard his Conscience in not answering sufficient. (HS, 34-35) ${ }^{36}$

Outra evidência importante de paridade tropológica entre Antônio e Southwell, proposta por John Klause, ocorre quando Bassanio, por carta, fica sabendo de suas perdas comerciais e da firme determinação de Shylock fazer valer, over-precise, os efeitos das leis do fictício Estado de Veneza para executar literalmente o seu contrato comercial sangrento. Bassanio diz: "paper as the body of friend,/ And every word in it a gaping wound" ("Como o corpo de um amigo é este papel./ E cada palavra nele contida é uma aberta ferida”. $M V, 3.2 .264-65$ ). Em Epistola de conforto, Southwell compara a laceração torturante da carne efêmera dos mártires a tiras de papel: "when [our executioners] thinke to have geven us and our cause the greatest wounde..., they stryppe us of slyght and paper harnesse” (“...quando [nossos carrascos] pensarem que provocaram uma grande ferida em nós e em nossa causa, [pense que] eles arrancam de nós [somente] pequenas tiras de papel...”. EC, 137r). ${ }^{37}$

Como sabemos, Shylock deseja fazer um uso rigorista (over-precise) e sangrento (provocando a deformação ou inversão diabólica nos efeitos potenciais) das virtudes civis das leis da fictícia Veneza ao pretender ter uma tira de carne de Antônio. Tudo isso é o efeito de um contrato (paper) de empréstimo feito para ajudar Bassanio em sua empresa de conquista da nobre herdeira de Belmonte. O termo do contrato (word) traz consigo o risco (hazard) de submeter Antônio a grande sofrimento (greatest wounde), figurando-o plenamente como um celibatário secular sacrificial (i.e., um 'jesuíta-mercador' ao modo de Southwell) capaz de arriscar a sua vida por amor (love) ao amigo.

Além disso, Southwell e Antônio têm visões comuns sobre a possibilidade de conversão e batismo do inimigo confessional por meio da força. Em sua linguagem cifrada "de mercador" em Epistola de conforto, Southwell fala de judeus como uma alegoria de seus verdadeiros inimigos confessionais na Inglaterra — os protestantes "heréticos" e suas "sinagogas

\footnotetext{
${ }^{35}$ Bass. (...) Eu vivo sob tormentos./ Por. Sim, mas temo que você fale sob tortura, /quando homens são forçados a dizer qualquer coisa.

${ }^{36}$ Quantas insuportáveis agonias temos sofrido sob tortura... [Alguém tão torturado] torna-se apto a dizer qualquer coisa para aliviar a agudeza e severidade da dor. [Mesmo um] laico ignorante preferiria arriscar a sua vida falando demais do que a sua consciência por não dizer o bastante.

${ }^{37}$ Apud KLAUSE, John. Catholic and protestant, jesuit and Jew, op. cit.
} 
do anticristo" 38 - cuja conversão ele pregava e teria regozijo de ver acontecer. Na literatura teatral elisabetana, era comum que alguns autores fizessem associaçóes alegóricas entre 'puritanos' e 'judeus', o que prevaleceu muito mais do que o hábito de alguns calvinistas franceses se referirem, em seus sermôes, a católicos como 'judeus' que cegamente acreditavam no mérito intrínseco das obras para a salvação. ${ }^{39}$

Portanto, a tópica de antagonismo que seria mais imediatamente crítica para a audiência/leitor elizabethano de $O$ mercador de Veneza opunha duas formas de precise: o mercador sacrificial, celibatário e papista (Antônio), que ambiguamente se coloca acima do amor conjugal; e o judeu-puritano (Shylock), que pretende, por vingança, fazer um uso rigorista (hipócrita) e carnal (vingança) das leis civis da fictícia Veneza. Por tal perspectiva, o choque entre Antônio ('papista') e Shylock ('puritano') poderia ser a expressão dramática dos problemas políticos trazidos para o Estado pela animosidade entre súditos pretensamente 'santos' e exclusivistas (recusantes ou antinomianos) em matérias de fé. Por outro lado, ao explorar o antagonismo entre Antônio e Shylock, até expor a inconsistência ou a hipocrisia de seus respectivos exclusivismos religiosos ou paixóes pelo absoluto, a teleologia dramática também explora o tema calvinista da iconoclastia do mérito.

\section{A iconoclastia do mérito e a figuração anti-precise do poder soberano}

A trama da peça sistematicamente torna inconsistente ou corrói o mérito de qualquer exclusivismo religioso, 'papista' ou 'puritano'. Assim, embora orgulhoso de seu combate à usura, que o tornava bem reputado entre seus pares 'cristãos' — sendo tratado por Gratiano como "royall Merchant" ${ }^{\text {— }}$-, o pretensamente caridoso e sacrificial Antônio não titubeia em recorrer ao 'usurário judeu', a quem odeia e sistematicamente ofendeu no passado, para financiar, com risco possível à sua vida e à soberania ducal, a moralmente contestável empresa de conquista de Bassanio em Belmonte, que redundará num notório "bad match" ambiguamente feminilizante para Bassanio. ${ }^{41}$ Aliás, Antônio é pivô, direto ou indireto, de três "bad matches": o casamento entre Bassanio e Portia; a fuga de Jessica enquanto Shylock se servia da sua mesa na noite de carnaval; e a suposta perda dos investimentos de Antônio. Falo em três "bad matches", pois, em um risível diálogo com Salarino - em prosa e cheio de trocadilhos obscenos — a respeito da fuga de Jessica, Shylock refere-se aos supostos prejuízos de Antônio - e, portanto, dele também — como "another bad match". ${ }^{42}$

Por sua vez, Shylock é moralmente inconsistente em seu exclusivismo religioso: diz a

\footnotetext{
${ }^{38}$ Apud Ibid.

${ }^{39}$ YARDENI, Myryam. French Calvinism and Judaism, op. cit.

${ }^{40}$ HEYES, Thomas (Ed.). The most excellent historie of the merchant of Venice, op. cit. p. 44.

${ }^{41}$ Ibid., p. $73-75$.

${ }^{42}$ Ibid., p. 36.
} 
Bassanio não aceitar dividir a sua mesa (e a sua fé) com os 'cristãos' ${ }^{43}$ mas aceita, por interesse mundano e ódio vingativo, dividir a mesa de Antônio, mesmo sabendo que se trata de uma bajulação hipócrita do 'cristão. ${ }^{44}$ Esta será a ocasião em que sua filha Jessica foge com o 'cristáo' Lorenzo ${ }^{45}$ o que não deixa de ser uma punição cômica à sua perfídia: seus herdeiros serão cristãos. Além disso, devemos lembrar que Shylock não se constrange de emprestar dinheiro e lucrar com a usura feita aos 'cristãos' de Veneza que sustentam sua mesa, cuja sobriedade é forçada por sua avareza. Portanto, seu exclusivismo religioso e sua gravidade patriarcal não têm nada de elevação espiritual. A sobriedade de sua mesa é fingida ${ }^{46}$ pois, na verdade, é um emblema paradoxal de afortunada avareza, ou seja, de prosperidade material destituída de caritas e misericórdia. Portanto, trata-se de uma vida centrada em exclusivismo confessional, mas esvaziada de santificação. ${ }^{47}$

A teleologia moral da peça afirma - por meio do jogo corrosivo de paradoxos na figuração dos motivos, tópicas e temas que caracterizam Antônio e Shylock - que o êxito material do moralmente inconsistente 'puritano' e o suposto malogro material do moralmente inconsistente 'papista' não dependem do (de)mérito moral de ambos. Somente depois que a situação é resolvida no tribunal e os protagonistas retornam para Belmonte é que se recebe a notícia, por meio de Portia, de que Antônio náo perdera seus principais investimentos. Por sua vez, Shylock recebe um tratamento mais suave das leis — por meio dos efeitos práticos criados pelo engenho casuístico-jurisdicionalista de Portia — do que estaria disposto a dar a Antônio. ${ }^{48}$

Como joga com a linguagem dos paradoxos, ${ }^{49}$ a peça não oferece nenhum esquema simples do tipo: 'Antônio/bem absoluto' e 'Shylock/mal absoluto'.50 Mesmo quando este é comicamente metaforizado, pelas costas, como demônio ou animal, os 'cristãos' que as-

\footnotetext{
${ }^{43}$ Ibid., p. 12.

${ }^{44}$ Ibid., p. 25.

${ }^{45}$ Ibid., p. 25-28.

${ }^{46}$ Ibid., p. $24-25$.

${ }^{47}$ Sobre este tipo de figuração negativa de 'puritano hipócrita', ver: BERGAMASCO, Lucia. Hagiographie et sainteté en Angleterre aux XVI ${ }^{\mathrm{e}}$-XVII' siècles, op. cit.

${ }^{48}$ HEYES, Thomas (Ed.). The most excellent historie of the merchant of Venice, op. cit. p. 53-64.

${ }^{49}$ A linguagem do paradoxo é geralmente acionada para atrair a atenção/desejo para determinados aspectos do mundo das experiências que serão, logo em seguida, desestabilizados por meio da exposição de dilemas insolúveis, da inconsistência de seus pressupostos ou da inconstância moral daqueles que os apregoam ou encarnam. No texto dramático shakespeariano, o uso desse recurso possibilita expor deliberadamente a artificialidade dos signos e das convençôes teatrais e sociais, mas com a finalidade moral de provocar na consciência do leitor/audiência um despertar iconoclasta conformista, ou seja, a figuração de paradoxos possibilita ensinar a infinita distância do mérito humano em relação à perfeição e graça divinas e, assim, enfatiza a necessidade do uso justo das instituiçôes e das leis civis, que seriam dádivas divinas para manterem unidos, na ordem civil, seres adversos, até o Juízo Final, quando caberia a Deus separar o 'joio' do 'trigo'. Ver: PLATT, Peter. Shakespeare and the culture of paradox, op. cit.

${ }^{50}$ Ver: DELUMEAU, Jean. História do medo no Ocidente, 1300-1800. São Paulo: Companhia das Letras, 2009. p. 414-461.
} 
sim agem são personagens vulgares ou moralmente inconstantes. Aliás, vale lembrar que muito da representação de Shylock como vilâo dramático, vingativo e over-precise em leis é contrabalançado pelo fato de ter sofrido recorrentes humilhações, o preconceito e o ódio religioso de Antônio, cuja suposta elevação moral de "royall Merchant" é sutilmente corroída na trama: ele é capaz de sacrificar-se por um ser mortal, moralmente pouco meritoso, como Bassanio, mas é incapaz de ser gentil e caridoso com Shylock. Em nome de sua amiticia com Bassanio, Antônio submete-se a um contrato cujo efeito paradoxal foi provocar o risco da inversão diabólica da finalidade caridosa das leis e das instituiçôes civis. ${ }^{51}$

A verdadeira contrapartida caridosa na peça é Portia, que é também o ponto de equilíbrio estrutural do gênero cômico teatral, pois, sem ela, não se cumpriria a convenção de finalizar a comédia resolvendo todas as adversidades. A intervenção engenhosa da virago virginal, disfarçada de juiz, lembra-nos que Antônio pôde sobreviver para desfrutar das boas notícias sobre as reais condiçóes de seus investimentos de além-mar porque pôde contar com sua proteção jurídica, ou seja, seus méritos de "royall Merchant" não lhe conferiam nenhum carisma protetivo. Bassanio e Portia estavam casados quando transcorre a cena do tribunal, mas não houve consumaçáo carnal, o que mantém a Diana de Belmonte como uma alegoria perfeita à Rainha Virgem até a última linha da peça. Além de ser uma óbvia alusão à rainha Elizabeth I, Portia (travestida de juiz, que é um ofício masculino tal como a dignidade régia encarnada por Elizabeth) faz, na cena do tribunal, uma emblemática arenga sobre a misericórdia como dom da graça que aperfeiçoa a dignidade régia: $:^{52}$

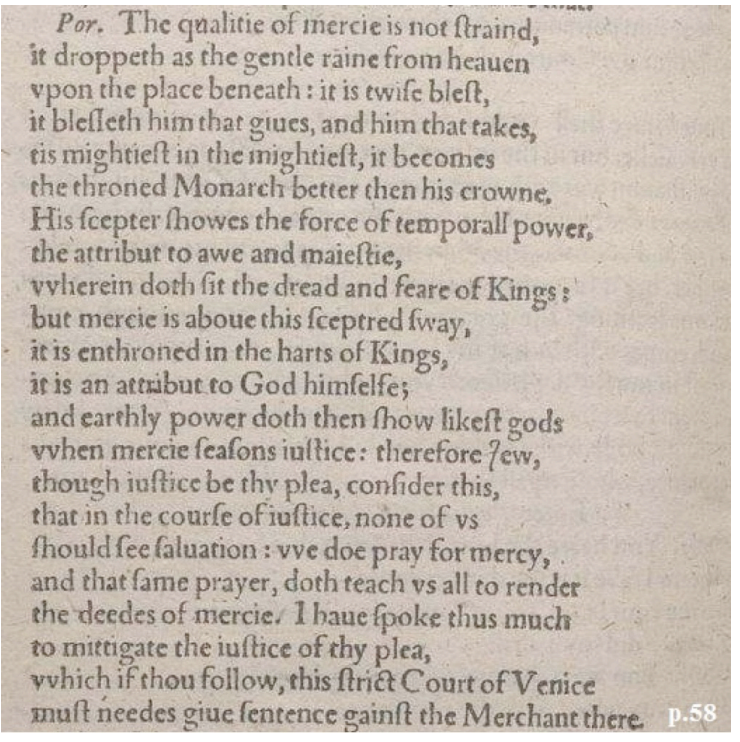

\footnotetext{
${ }^{51}$ HEYES, Thomas (Ed.). The most excellent historie of the merchant of Venice, op. cit. p. 53-55.

52 Ibid., p. 58.
} 
Portia. A virtude da misericórdia não é forçada.

Ela cai do céu, como chuva suave,

nos lugares mais baixos. Ela abençoa duplamente:

aquele que a oferta e aquele que a recebe.

É a mais poderosa entre as mais poderosas virtudes.

Torna o Monarca entronizado melhor do que sua coroa...

Seu cetro representa a força do poder temporal,

o medo reverente e a majestade, em que se assentam

o temor respeitoso e o pavor pelos Reis.

Mas a misericórdia paira acima do poder secular:

está entronizada nos coraçôes dos Reis;

é um atributo do próprio Deus...

Então, o poder terreno mais se assemelha ao divino

quando a misericórdia tempera a justiça. Portanto, Judeu,

embora justiça seja teu pleito, considere isso:

Que [somente] no curso da justiça nenhum de nós

teria salvação. Nós rogamos por misericórdia;

e esta mesma devota petição ensina todos nós a realizarmos

ações de misericórdia. Assim, muito falei

para mitigar a justiça de teu pleito,

no qual, se tu persistires, esta rigorosa Corte de Veneza

precisará dar sentença contra aquele Mercador...

Na teologia calvinista episcopal elisabetana, os dons da graça não podem ser adquiridos ou forçados por engenho ou mérito humano. Assim, este trecho da peça estabelece um nítido contraste (teológico e moral) entre o precisianist Shylock e a graça divina régia. Ora, como Shylock não demonstra misericórdia e mantém firme o propósito de fazer uso rigorista (over-precise) das leis contra Antônio, isso evidencia que não é eleito e que, portanto, falha como Santo Visivel. O Santo Visivel é o protestante que, por meio do autoexame espiritual incessante, busca fazer com que seus atos externos na vida civil e doméstica estejam de acordo com os sinais da graça que percebe haver em seu coração, visando a atingir, ao final de um longo e tortuoso processo, a certeza de estar entre os eleitos. ${ }^{53}$ Para a teologia política episcopal e para os puritanos moderados, ${ }^{54}$ a santificação da vida cotidiana como preparação da bem-aventurança na graça não é antitética à obediência à ordem civil e eclesiástica elisabetana.

\footnotetext{
${ }^{53}$ BERGAMASCO, Lucia. Hagiographie et sainteté en Angleterre aux XVI ${ }^{e}$-XVII siècles, op. cit.

${ }^{54}$ LAKE, Peter. Moderate puritans and Elizabethan Church, op. cit. BERGAMASCO, Lucia. Hagiographie et sainteté en Angleterre aux XVI ${ }^{\mathrm{e}}$-XVII ${ }^{\mathrm{e}}$ siècles, op. cit.
} 
O fundamento teológico do Santo Visivel é a doutrina do Pacto de Deus com Abraão, segundo a qual o fiel se compromete - privadamente, coletivamente e, muitas vezes, por escrito - a consagrar a sua vida a Deus e se engrandecer na graça. Trata-se, portanto, de uma reelaboração Godly do calvinismo, associada à ideia de espiritualização do cotidiano e à intensificação da vida devocional..$^{55} \mathrm{Na}$ peça, Shylock cita Abraão fora de contexto, ou seja, tem o seu exemplo moral na boca, mas não no coração, o que é uma forma de compor um estereótipo cênico risível de puritano hipócrita. Diante da sua teimosia, do seu rigorismo legal e da sua dureza de coração, caberá à engenhosidade jurisdicionalista da virago virginal Portia o papel de preservar os privilégios de 'Veneza' e evitar o uso sangrento das leis - i.e., a inversão ou rebaixamento diabólico do significado divino das leis e instituiçóes civis.

Em certa medida, por meio da figuração de Portia como juiz, ${ }^{56}$ a peça sugere o ideal de equilíbrio dinâmico casuístico que deve haver entre Rex e Lex, ou seja, o exercício de um poder soberano capaz de submeter-se à lei para proteger os súditos no quadro das leis, mas também capaz de evitar o uso tirânico e hipócrita das leis nas demandas por justiça. ${ }^{57}$ Para o calvinismo episcopal elisabethano, a ordem civil foi instituída por Deus para manter seres paradoxais e adversos (eleitos e réprobos) protegidos, submissos e indistintos, até o Juízo Final, na exterioridade civil de vida cristá. Todas essas premissas fazem parte das sutilezas de temas e tópicas no enredo e na caracterizaçáo dos personagens da peça, e ratificam o princípio teológico calvinista episcopal elisabetano de que o mérito humano não move a vontade divina para a salvação, reforçando a noção de iconoclastia do mérito em consonância com a crítica anti-precise aos exclusivismos 'Santos' de recusantes católicos e puritanos antinomianos. ${ }^{58}$

\section{Os perigos da melancolia e da idolatria para a ordem civil}

Postulamos que Antônio e Shylock estão mutuamente implicados como figuraçôes de ameaça ao corpo político, particularmente quando Antônio aceita, de forma inconsequente, os termos sangrentos do contrato de empréstimos de Shylock, cuja execução literal implicaria provocar a inversão diabólica e tirânica no uso das instituiçôes e das leis civis da fictícia Veneza. Agora, devemos abordar como a peça oferece evidências tropológicas plausíveis que expliquem a predisposição ao sacrifício em Antônio, e como tais evidências sugerem que se trata de uma obra sacrificial carnal e não de uma autêntica expressão de caritas.

\footnotetext{
${ }^{55}$ BERGAMASCO, Lucia. Hagiographie et sainteté en Angleterre aux XVI ${ }^{e}$-XVII siècles, op. cit.

${ }^{56}$ HEYES, Thomas (Ed.). The most excellent historie of the merchant of Venice, op. cit. p. 53-63.

57 VIGNAUX, Michèle. Gloriana: Elizabeth I d'Angleterre ou la gloire incarnée. HES, v. 20, n. 2, p. 151-161, 2001.

${ }^{58}$ CURRAN JR., John E. Jacob and Esau and the iconoclasm of merit. SEL, v. 49, n. 2, p. 285-309, 2009; VIANNA, Alexander Martins. As figuraçóes de rei e a caracterização de 'puritano' e 'papista' em Basilikon Doron, op. cit.
} 
A possibilidade de Antônio ser um inconsequente innamorato em açóes e escolhas é sugerida no começo da peça, quando o personagem é envolto por um aparentemente inexplicável humor melancólico. ${ }^{59}$ Antes mesmo de a palavra "melancholy" aparecer na fala de Gratiano ao se referir à tristeza de Antônio, ${ }^{60}$ a própria sequência cênica sutilmente explica por que Antônio - malgrado sua prosperidade nos negócios - encena o melancólico no "teatro do mundo": 61 ele esperava a visita de Bassanio e já conhecia o assunto a ser tratado, tanto que toma a iniciativa de abordá-lo. ${ }^{62}$

Ao longo das seis primeiras páginas de Q1, é envolta em mistério a razão da melancolia de Antônio - ele mesmo só responde ao assunto com interjeiçôes e versos evasivos —, mas fica sugerido que a sua afortunada tristeza - em si mesma tão moralmente paradoxal quanto a afortunada avareza de Shylock - decorre do seu conhecimento prévio da empresa de casamento de Bassanio. Não por acaso, as três páginas de diálogo que antecipam a chegada de Bassanio são dedicadas a jogos cênicos e trocadilhos cômicos que enfatizam que Antônio está melancólico, especulam suas causas e sugerem que sua tristeza parece fora de lugar.

A figuração da melancolia de Antônio cria um vínculo implicativo causal, na trama da peça, com sua propensão de abrir a senda para o mal diabólico, o que é metaforizado, várias vezes, por meio do 'judeu/puritano' cênico Shylock. A exemplo da tipologia de Robert Burton (1577-1640), os tratados morais e médicos dos séculos XVI e XVII — e suas transposiçôes em tipos dramáticos - estavam marcados pela teoria dos humores. $\mathrm{Na}$ tipologia médica-teológica de Burton, a melancolia amorosa é o avesso moral das virtudes do amor, pois, ao provocar a imoderação, transforma uma virtude espiritual em vício carnal, invertendo os efeitos moralmente saneadores e cívicos da caridade e da boa-vontade com o próximo.

Em inglês elizabethano, love pode ser utilizado para se referir ao amor caridoso sacrifcial pelo próximo a exemplo de Cristo (caritas), ao amor conjugal e ao amor amical no sentido clássico-renascentista (amiticia). Este último sentido pode significar amizade entre indivíduos, amizade entre Estados e amizade entre indivíduo e Estado. No entanto, em $O$ mercador de Veneza, a amiticia entre Antonio e Bassanio, deformada em vício carnal pela melancolia amorosa, surge como condição de possibilidade do contrato sangrento com Shylock. Assim, podemos dizer que os papistas cênicos Antonio e Bassanio aceitaram o hazard de fazerem com que seu love se desdobrasse num transtorno diabólico puritano para o duque. Portanto, a peça propóe um vínculo implicativo causal entre ameaças 'puritanas' e 'papistas' à ordem civil e ao poder soberano divino.

O amor/desejo (love) excessivo voltado a seres mortais (pessoas e coisas) inverte a relaçáo entre significantes imanentes e significados ou referentes transcendentes na figuraçáo da caritas cristã. Isso é considerado uma forma de manifestação de superstição idólatra pela crí-

\footnotetext{
${ }^{59}$ HEYES, Thomas (Ed.). The most excellent historie of the merchant of Venice, op. cit. p. 3-8.

${ }^{60}$ Ibid., p. 6.

${ }^{61}$ Ibid., p. $4-5$.

${ }^{62}$ Ibid., p. 6.
} 
tica teológica douta episcopal elisabetana, expressa em tratados teológicos e no sermonário oficial. ${ }^{63}$ Se considerarmos as tipologias de melancolia amorosa de Burton, podemos afirmar que, no jogo tópico de antagonismo entre Shylock e Antônio, o amor desmedido deste último por Bassanio é colocado no mesmo patamar de vício carnal da avareza usurária de Shylock, que é o desejo desmedido por dinheiro. Contudo, para equilibrar o jogo de paradoxo e evitar o maniqueísmo 'bem absoluto'(Antônio)/'mal absoluto'(Shylock), a teleologia da peça tem o cuidado de mostrar que o ódio vingativo de Shylock não é gratuito ou fortuito, mas provocado pelo próprio Antônio, que lucra como mercador, mas periodicamente combate a usura do 'judeu' e ofende sua nação.

Assim, ambos ficam numa posição dramática de vilania moralmente paradoxal, mas equivalente, pois o choque de suas carnalidades inconsequentes (ódio vingativo de Shylock vs. idolatria amorosa de Antônio $\rightarrow$ avareza de Shylock vs. liberalidade excessiva de Antônio), condensado num acordo comercial sangrento, inverte diabolicamente os efeitos virtuosos das leis e das instituiçóes de Veneza, obliterando a segurança do bem-comum e as prerrogativas divinas do poder soberano, quais sejam: ser o servo da lei e o senhor da justiça/equidade a temperar casuisticamente os efeitos da aplicaçáo das leis e dos costumes do corpo político. Portanto, há um equilíbrio não maniqueísta nesta paradoxal polarização de protagonistas excessivamente carnais: o ódio exclusivista e vingativo de Shylock é nascido do choque dialético com o ódio exclusivista e hipócrita de Antônio, mas só tem efeito potencialmente destrutivo à ordem civil por causa da idolatria amorosa de Antônio, expressa na liberalidade excessiva (de corpo e bens) com Bassanio, que o leva a aceitar um contrato comercial perigoso para si e para o corpo político.

O jogo de negócios (circulação de bens, pessoas e dinheiros) que torna Veneza próspera depende do uso virtuoso de suas leis. $\mathrm{O}$ uso adequado do dinheiro e das leis promove a sua ordem civil (i.e., o bem comum, que é a expressáo cívica de caritas). Tal ordem civil mostra as benesses públicas de uma relação adequada com o dinheiro e com as leis. Nesse sentido, a avareza e a falta de misericórdia de Shylock são o antítipo moral, ou avesso diabólico, dessa ordem cívica indiciada na figura virtuosa do duque. Como emblema de avareza e ausência de misericórdia, Shylock tem o potencial de criar um efeito destrutivo para o uso do dinheiro e das leis em Veneza, mas tal possibilidade nasce dialeticamente das paixóes absolutas do melancólico Antônio: o ódio religioso e a idolatria amorosa.

Deste modo, podemos observar uma escolha coerente de motivos para caracterizar os polos corrosivos precise da peça, mas seu jogo depende da plausibilidade (hu)moral de um gatilho para a trama: a melancolia amorosa, expressa na abertura da peça, que caracteriza a predisposição de Antônio de morrer pelo amigo e que investe de ambiguidade carnal sua abnegação amorosa e celibatária a Bassanio, transformando este num perfeito ídolo de mente e

${ }^{63}$ DIEHL, Huston. Staging reform, reforming the stage, op. cit.; CROCKETT, Bryan. The play of paradox, op. cit. 
coração característico dos innamorati melancólicos da literatura elisabetana. Como Antônio tem um ser mortal como fim maior de seu amor, fazendo disso um risco para a ordem civil, sua obra caridosa revela-se ser, na verdade, um engodo carnal, o que compóe o estereótipo de 'jesuíta/papista' (e suas hipócritas obras carnais com pretensão soteriológica) característico da crítica do sermonário calvinista e do repertório literário anticatólico elizabethano. ${ }^{64}$

\section{Conclusão}

Desde meados da década de 1980, vem se consolidando um nicho de estudos shakespearianos focado na reconstituição da legibilidade da linguagem religiosa nas diferentes materialidades editoriais de peças do corpus shakespeariano. Alguns trabalhos têm se notabilizado por identificar a tendência trópica de feminilização ginofóbica, carnavalização, carnalização, demonização e animalização do inimigo confessional na literatura e dramaturgia elisabetana e jacobita como algumas das formas de manifestação das polêmicas anticatólicas e antipuritanas na Inglaterra. Na peça $O$ mercador de Veneza, há o rebaixamento carnal do tema do amor (love) quando este é associado aos riscos de idolatria amorosa, morte violenta e desordem civil.

Há uma série de indícios na peça que sugerem este tipo de rebaixamento carnal do amor sacrificial de Antônio: este situa seu amor por Bassanio acima do amor conjugal entre Bassanio e Portia; é representado como mercador secular e celibatário (como uma alegoria cênica de 'jesuíta' e suas obras carnais), não formando casal ao final da peça, o que lhe confere uma posiçấo arrogante de outsider no mundo do amor conjugal de Belmonte; em nome deste mesmo amor de outsider, Antônio aceitou os efeitos de um contrato sangrento que poderia criar um efeito diabolicamente corrosivo para as leis e as instituiçôes civis, que são dádivas de Deus que expressam a Sua caritas; o contrato assinado por Antônio e Shylock cria o efeito paradoxal de anular o duque como centro soberano da justiça e da equidade, além do risco moral de criar um efeito sangrento e tirânico para as leis protetivas do Estado.

A linguagem da amizade na peça sobrepóe as três possibilidades semânticas de amiticia, mas para provocar deliberadamente efeitos paradoxais na relaçáo entre proteçâo e confiança das/nas leis do Estado: a forma como é conduzida a amiticia entre Bassanio e Antônio cria um transtorno para a amiticia entre Antonio e o duque, que representa o poder civil soberano de Veneza; se o duque exercitasse a sua amiticia para proteger Antônio dos efeitos legais do seu contrato com Shylock, isso abalaria a confiança nas leis de Veneza e, portanto, a sua relaçáo de amiticia com outros Estados e indivíduos.

${ }^{64}$ GRIFFIN, Benjamin. The birth of the history play: saint, sacrifice, and reformation. SEL, v. 39, n. 2, p. 217-237, 1999; KNAPP, Jeffrey. Preachers and players in Shakespeare's England. Representations, n. 44, p. 29-59, 1993; MILTON, Anthony. Catholic and Reformed, op. cit.; DIEHL, Huston. Staging reform, reforming the stage, op. cit.; CROCKETT, Bryan. The play of paradox, op. cit. 
Entâo, a solução para o Duque não seria abrir um precedente de quebra do contrato, pois isso provocaria a destruição do comércio de Veneza, mas combater os paradoxos precise potencialmente destrutivos ao Estado (ou à vida de um súdito) por meio de um paradoxo legalmente engenhoso e restaurador do magistrado soberano como centro da justiça e equidade: exigir que o contrato fosse rigorosamente cumprido, ou seja, sem derramar sangue e com o peso exato da tira de carne. ${ }^{65}$ Portanto, depois de o duque e Portia terem tentado persuadir Shylock a fazer o uso virtuoso da caritas, Portia joga engenhosamente com os paradoxos da relação Shylock/Antônio ao provocar o impedimento do uso precise das leis por Shylock ao exigir deste justamente seu cumprimento precise, figurando o ideal de um poder soberano capaz de submeter-se às leis para salvar os súditos no quadro das leis do Estado.

Como alegoria instrutiva e crítica para a rainha Elizabeth I, cabe a Portia, na figura de juiz disfarçado (um ofício masculino, tal como a dignidade régia encarnada por Elizabeth), trazer a efetiva lição civil e teológica de caridade para a fictícia Veneza (alegoria de Inglaterra), ao usar todo o seu engenho legal e retórico para evitar um uso ou efeito over-precise das leis tanto contra Antônio quanto contra Shylock. Um uso over-precise das leis significaria o esvaziamento do poder régio como centro soberano da justiça, misericórdia e equidade, cujo mandato divino cobra um discernimento devidamente cultivado para haver sabedoria na forma de temperar os efeitos das leis do Estado e, assim, casuisticamente, fazer da proteção do bem comum uma autêntica expressão civil de caritas.

Artigo recebido em 5 de maio de 2013 e aceito em 3 de julho de 2013.

*Este artigo é um dos produtos do projeto de pesquisa "Reforming Shakespeare": materialidade textual, ordem pública e idolatria (2010-2013), financiado: pela Faperj, na forma de APQ1 (2010-2011) e bolsas de I.C. (2010-2012); pelo CNPq, na forma de bolsa de I.C. (2010-2011); e pela Capes, na forma de bolsa (2012-2013) do Programa Jovens Talentos Científicos (PJTC/Capes).

** Doutor em história social pela Universidade Federal do Rio de Janeiro. Professor adjunto II de história moderna do Departamento de História da Universidade Federal Rural do Rio de Janeiro. Rio de Janeiro, RJ, Brasil. E-mail: alexvianna1974@hotmail.com.

${ }^{65}$ HEYES, Thomas (Ed.). The most excellent historie of the merchant of Venice, op. cit. p. 61-63. 